\title{
Occurrence of Aeromonas species and Plesiomonas shigelloides in patients with and without diarrhoea in Lagos, Nigeria
}

\section{S. A. ALABI and T. ODUGBEMI}

Department of Medical Microbiology and Parasitology, College of Medicine, University of Lagos, P.M.B. 12003, Lagos, Nigeria

Summary. The prevalence of Aeromonas spp. and Plesiomonas shigelloides was determined in patients attending the enteric laboratory of the Department of Medical Microbiology and Parasitology, Lagos University Teaching Hospital, Nigeria. During the 12-month study (October 1986-September 1987), Aeromonas spp. were isolated from $53(2.26 \%)$ of 2350 patients with diarrhoea and only $2(0.4 \%)$ of 500 patients without diarrhoea $(\mathrm{p}<0.01)$. Similarly, $P$. shigelloides was isolated from $16(0.68 \%)$ patients with diarrhoea and none of the controls $(\mathrm{p}>0.05)$. The seasonality, age and sex distribution of diarrhoea associated with Aeromonas spp. and $P$. shigelloides in this study were similar to those of diarrhoea associated with other recognised enteropathogens in Nigeria. Both species may play a role in the aetiology of acute diarrhoeal disease in that environment.

\section{Introduction}

In recent years, reports of the isolation of Aeromonas spp. or Plesiomonas shigelloides from patients with diarrhoea in different parts of the world have increased. This development has no doubt increased the level of awareness of their potential pathogenic role and geographical spread. Some authors have proposed Aeromonas or Plesiomonas spp. as causes of acute diarrhoeal disease (Sanyalet al., 1975; Rutala et al., 1982; Agbonlahor, 1983; Ljungh and Wadstrom, 1985; Reinhardt and George, 1985), but others have been unable to ascribe any clinical significance to these organisms (Pitarangsi et al., 1982; Figura et al., 1986). Their importance as agents of diarrhoea is, therefore, still controversial and subject to continuing investigation in many parts of the world.

In Nigeria, as in most other West African countries, little is known about diarrhoea associated with Aeromonas spp. or $P$. shigelloides. In this paper, we report on the prevalence of these species in patients attending the Lagos University Teaching Hospital (LUTH) in Nigeria and comment on their possible roles in diarrhoeal episodes in that environment.

Received 24 July 1989; accepted 31 Oct. 1989.

\section{Materials and methods}

\section{Patients and sources of isolates}

The study included 2350 patients with diarrhoea and 500 patients without diarrhoea (controls) who submitted faecal specimens for culture at the enteric laboratory of the Department of Medical Microbiology and Parasitology, LUTH, from October 1986 to September 1987. Diarrhoea in this study was defined as three or more loose stools a day within 2 days of specimen collection. Patients in the control group had no diarrhoea in the 2 weeks before specimen collection. Other data obtained on each patient included age, sex, general medical history and accompanying clinical features.

\section{Isolation and identification of Aeromonas and Plesiomonas spp.}

Freshly collected faecal specimens were plated on to xylose desoxycholate citrate agar (XDCA) and sheepblood agar containing ampicillin $15 \mu \mathrm{g} / \mathrm{ml}$ (ABA). These media are recommended for the isolation of these organisms from specimens such as faeces (Millership and Chattopadhyay, 1984; Agger et al., 1985). In addition, alkaline peptone water, pH 8.6 (APW), was used as an enrichment medium for both organisms.

Cultures were incubated at $37^{\circ} \mathrm{C}$ for $18-24 \mathrm{~h}$, after which non-xylose-fermenting colonies on XDCA and all colonies on ABA were screened for oxidase production 
(Kovacs, 1956). Oxidase-positive colonies were subcultured on to nutrient-agar plates (Oxoid). They were further confirmed as Aeromonas spp. or P. shigelloides according to the criteria outlined by von Graevenitz (1985).

\section{Isolation of other bacterial enteropathogens}

Specimens were also inoculated on to MacConkey agar (MAC), desoxycholate citrate agar (DCA), and thiosulphate-citrate-bile salt-sucrose agar (TCBS). In addition, appropriate enrichment broths were used to enhance the isolation of Salmonella spp., Shigella spp., Vibrio cholerae and Yersinia enterocolitica. Incubation was at $37^{\circ} \mathrm{C}$ for 18-24 h except for cultures for $Y$. enterocolitica which were incubated at room temperature $\left(22^{\circ}-25^{\circ} \mathrm{C}\right)$ for $48 \mathrm{~h}$.

On primary isolation, suspicious colonies were screened by subculture on Kligler iron agar (KIA) and motilityindole-urea medium (MIU). Further identification of isolates was by standard biochemical tests as described by Cowan (1974). Serological confirmation of identification was by slide agglutination with Wellcome antisera (Wellcome Reagents Ltd, Wellcome Research Laboratories, Beckenham).

For economic reasons, culture for Campylobacter spp. was not performed.

\section{Statistical analysis}

Results were analysed statistically by the $\chi^{2}$ test (Colton, 1974).

\section{Results}

Of the 2350 faecal specimens from patients with diarrhoea processed during this study, Aeromonas spp. were isolated from $53(2 \cdot 26 \%)$, P. shigelloides from $16(0 \cdot 68 \%)$, Shigella spp. from $4(0 \cdot 17 \%)$, Salmonella spp. from $3(0 \cdot 13 \%)$ and Y. enterocolitica from $2(0.09 \%)$. Enteropathogenic Escherichia coli (EPEC) strains were isolated from $39(2.85 \%)$ of 1368 specimens examined. $V$. cholerae was not isolated from any of the specimens processed.

Only two strains of Aeromonas spp. and no other recognised bacterial pathogens were isolated from 500 faecal specimens from control patients included in this study. Statistically, Aeromonas spp. were isolated significantly more often from patients with diarrhoea than from controls $\left(\chi^{2}=7 \cdot 5, \mathrm{p}<0.01\right)$. For $P$. shigelloides, the difference between the two groups was not statistically significant $\left(\chi^{2}=3 \cdot 43\right.$, $\mathrm{p}>0.05$ ).

In this study, clinical features of diarrhoea associated with Aeromonas spp. and $P$. shigelloides were similar to those of diarrhoea due to other known bacterial enteropathogens. There was abdominal pain in $3(5.7 \%)$, anorexia in $4(7.6 \%)$, vomiting in $5(9.4 \%)$ and weight loss in $3(5.7 \%)$ of 53 patients from whom Aeromonas spp. were isolated. Similarly, there was abdominal pain in 2 $(12.5 \%)$, anorexia in $2(12.5 \%)$, vomiting in $1(6.5 \%)$ and weight loss in $1(6.5 \%)$ of 16 (patients with diarrhoea associated with $P$. shigelloides.

The distribution of cases of diarrhoea associated with Aeromonas spp. and $P$. shigelloides according to age and sex of patients is shown in the table. There were $20(37.7 \%)$ episodes related to Aeromonas spp. in males and $33(62.2 \%)$ in females. On the other hand, more diarrhoea associated with $P$. shigelloides occurred in males $(10 ; 62.5 \%)$, than in females $(6 ; 37.5 \%)$. However, the difference in sex distribution of isolates was not statistically significant $\left(\chi^{2}=3.5, p>0.05\right)$. Furthermore, diarrhoea due to these two organisms affected all age groups. However, $23(43.4 \%)$ of cases of diarrhoea associated with Aeromonas spp. occurred in children under 5 years of age, whereas $7(13.2 \%)$ of such episodes occurred in patients over 70 years old. Similarly, 3 cases $(18.8 \%)$ of diarrhoea associated with $P$. shigelloides occurred in the very young and 5 cases $(31.3 \%)$ occurred in the very old. Also, the majority of our strains were isolated during the wet months of July-October.

\section{Discussion}

This prospective 12-month study has shown that Aeromonas spp. and $P$. shigelloides are found in association with diarrhoea more often than in controls in our environment. In fact, Aeromonas spp. were isolated significantly more often from patients with diarrhoea than from controls $(\mathrm{p}<$ 0.01 ). Furthermore, isolation rates of $2.26 \%$ for Aeromonas spp. and $0.68 \%$ for $P$. shigelloides from patients with diarrhoea were similar to those of recognised enteric pathogens obtained in this study. These findings suggest that both organisms, but particularly Aeromonas spp., can cause acute diarrhoea in patients in Lagos.

In similar studies in other parts of the world, workers have reported an isolation rate of less than $1 \%$ for Aeromonas spp. in normal subjects (Pauckova and Fukalova, 1968; Burke et al., 1983). Similarly, Arai et al. (1980) found P. shigelloides in the faeces of only $3(0.01 \%)$ of 38454 normal subjects examined in Japan. However, both Echeverria et al. (1981) and Pitarangsi et al. (1982) found no difference in the isolation of these organisms from normal controls and patients with diarrhoea in Thailand. Therefore, we agree with an earlier suggestion by Agger et al. (1985) that these divergent results may be related to geographical location, 
Table. Distribution of cases of diarrhoea associated with Aeromonas spp. and $P$. shigelloides by age and sex

\begin{tabular}{|c|c|c|c|c|c|c|}
\hline \multirow{2}{*}{$\begin{array}{c}\text { Age } \\
\text { (years) }\end{array}$} & \multicolumn{3}{|c|}{ Aeromonas spp. } & \multicolumn{3}{|c|}{ P. shigelloides } \\
\hline & Male & Female & Total & Male & Female & Total \\
\hline $0-5$ & 8 & 15 & 23 & 2 & 1 & 3 \\
\hline $6-10$ & 2 & 4 & 6 & 1 & & 1 \\
\hline $11-20$ & 1 & 3 & 4 & 1 & 2 & 3 \\
\hline $21-30$ & 3 & 4 & 7 & 2 & $\ldots$ & 2 \\
\hline $31-40$ & .. & 1 & 1 & 1 & $\ldots$ & 1 \\
\hline $41-50$ & 1 & $\ldots$ & 1 & 1 & $\ldots$ & 1 \\
\hline $51-60$ & $\ldots$ & 1 & 1 & $\ldots$ & $\ldots$ & $\ldots$ \\
\hline $61-70$ & 1 & 2 & 3 & 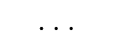 & $\ldots$ & $\ldots$ \\
\hline $71-80$ & 1 & 3 & 4 & 1 & $\ldots$ & 1 \\
\hline $81-90$ & 1 & $\ldots$ & 1 & & 1 & 1 \\
\hline $91-100$ & 2 & $\ldots$ & 2 & 1 & 2 & 3 \\
\hline Total & 20 & 33 & 53 & 10 & 6 & 16 \\
\hline$(\%)$ & $(37.7 \%)$ & $(62 \cdot 3 \%)$ & (100) & $(62.5 \%)$ & $(37.5 \%)$ & $(100)$ \\
\hline
\end{tabular}

season of collection, and the microbial media used for isolation.

Diarrhoea associated with Aeromonas and Plesiomonas spp. appeared to affect all age groups, but particularly children under the age of 5 years (table). Also, more Aeromonas spp. were isolated from females than males in this study, while the reverse was the case for $P$. shigelloides. In an earlier report by Agbonlahor (1983), two out of six Aeromonas strains isolated from patients in Lagos with acute diarrhoea were from children.

Clinical features of diarrhoea associated with Aeromonas and Plesiomonas spp. in this study included abdominal pain, anorexia, vomiting and weight loss. These features were not distinct from those of diarrhoea due to recognised enteropathogens. Furthermore, most of our strains were isolated during the warm and wet months of the year. This is in agreement with earlier suggestions that the association of Aeromonas and Plesiomonas spp. with water may be responsible for the apparent seasonality in the incidence of diarrhoea associated with these agents (Burke et al., 1983; Agger et al., 1985; Reinhardt and George, 1985). There have been some reports that Aeromonas spp. and $P$. shigelloides

\section{REFERENCES}

Agbonlahor D E 1983 The role of Aeromonas in acute diarrhoeal diseases in Nigeria. Central African Journal of Medicine 29: $142-145$.

Agger W A, McCormick J D, Gurwith M J 1985 Clinical and microbiological features of Aeromonas hydrophila-associated diarrhea. Journal of Clinical Microbiology 21 : 909-913.

Arai T, Ikejima N, Itoh T, Sakai S, Shimada T, Sakazaki R 1980 A survey of Plesiomonas shigelloides from aquatic cause a more severe form of diarrhoea in immunocompromised hosts, thereby suggesting an opportunist role for these organisms (Ljungh and Wadstrom, 1985). In this study, clinical conditions that might have predisposed to Aeromonas-associated diarrhoea were less frequent, and these were peptic ulcer in $3(5.7 \%)$ and kwashiorkor in $1(1.9 \%)$ of our patients. Similarly, there was only one case each of diabetes mellitus and kwashiorkor in a total of 16 patients with Plesiomonas-associated diarrhoea.

In conclusion, results of this study strongly suggest an aetiological role for both organisms, but particularly Aeromonas spp. in diarrhoeal disease in Nigeria. However, for a better understanding of the epidemiology of diarrhoea that may be due to these organisms, there is a need for related community-based studies. Meanwhile, routine culture of these organisms from faecal specimens of patients with diarrhoea is advised to determine their level of involvement in such infections.

We are grateful to Dr D. M. Jones, Public Health Laboratory, Withington Hospital, Manchester, for providing us with a control strain of $A$. hydrophila and $P$. shigelloides for use in this study.

environments, domestic animals, pets and humans. Journal of Hygiene 84: 203-211.

Burke V, Gracey M, Robinson J, Peck D, Beaman J, Bundell C 1983 The microbiology of childhood gastroenteritis: Aeromonas species and other infective agents. Journal of Infectious Diseases 148: 68-74.

Colton T 1974 Statistics in Medicine. Little, Brown \& Co, Boston.

Cowan S T 1974 Cowan and Steel's Manual for the identification 
of medical bacteria, 2nd edn. Cambridge University Press, Cambridge.

Echeverria P, Blacklow N R, Sanford L B, Cukor G G 1981 Travellers' diarrhea among American Peace Corps volunteers in rural Thailand. Journal of Infectious Diseases 143: 767-771.

Figura N, Marri L, Verdiani S, Ceccherini C, Barberi A 1986 Prevalence, species differentiation, and toxigenicity of Aeromonas strains in cases of childhood gastroenteritis and in controls. Journal of Clinical Microbiology 23 : 595-599.

von Graevenitz A 1985 Aeromonas and Plesiomonas. In: Lennette E $\mathrm{H}$ et al. (eds) Manual of clinical microbiology, 4th edn. American Society for Microbiology, Washington, DC pp 278-281.

Kovacs N 1956 Identification of Pseudomonas pyocyanea by the oxidase reaction. Nature 178: 703.

Ljungh A, Wadstrom T 1985 Aeromonas and Plesiomonas as possible causes of diarrhoea. Infection 13: 169-173.

Millership S E, Chattopadhyay B 1984 Methods for the isolation of Aeromonas hydrophila and Plesiomonas shigelloides from faeces. Journal of Hygiene 92 : 145-152.

Pauckova V, Fukalova A 1968 Occurrence of Aeromonas hydrophila and Aeromonas shigelloides in feces. Zentralblatt fur Bakteriologie. I. Abteilung Originale 206: 212-216.

Pitarangsi C et al. 1982 Enteropathogenicity of Aeromonas hydrophila and Plesiomonas shigelloides: Prevalence among individuals with and without diarrhoea in Thailand. Infection and Immunity 35 : 666-673.

Reinhardt J F, George W L 1985 Plesiomonas shigelloidesassociated diarrhea. Journal of the American Medical Association 253: 3294-3295.

Rutala W A, Sarubi F A, Finch C S, MacCormack J N, Steinkraus G E 1982 Oyster-associated outbreak of diarrhoeal disease possibly caused by Plesiomonas shigelloides. Lancet iii : 739.

Sanyal S C, Singh S J, Sen P C 1975 Enteropathogenicity of Aeromonas hydrophila and Plesiomonas shigelloides. Journal of Medical Microbiology 8: 195-198. 